\title{
Hepatic dysfunction in falciparum and vivax malaria in Northern India
}

\author{
Omesh Goyal, Subhadra Prashar, Sandeep Puri \\ Department of Gastroenterology, Dayanand Medical College and Hospital, Ludhiana, Punjab, India
}

\begin{abstract}
Background and Objectives: Hepatic dysfunction is known to occur in Plasmodium falciparum malaria with varied incidence in different regions. Recent studies report liver involvement in P. vivax infection also. It is important to know about this entity in order to recognize it early and offer prompt and specific treatment. The present study aimed to assess the incidence, pattern, severity and outcome of hepatic dysfunction in cases of P. falciparum and P. vivax malaria admitted to a tertiary care hospital in northern India. Materials and Methods: This retrospective study included all hospitalized patients diagnosed to have malaria from January 2013 to December 2013. Their clinical and biochemical parameters, complications and outcome were recorded. Results: Of 115 patients included, $85(73.9 \%)$ had $P$. vivax infection and $30(26.1 \%)$ had $P$. falciparum infection. The mean age was $36.7 \pm 16.1$ years and male:female ratio was $2.7: 1$. Hepatic dysfunction was seen in $31.8 \%(27 / 85)$ patients of vivax malaria and $50 \%(15 / 30)$ patients of falciparum malaria $(\mathrm{p}=0.082)$. The mean bilirubin, AST and ALT in patients with hepatic dysfunction were $7.7 \pm 7.3 \mathrm{mg} / \mathrm{dL}, 97.1 \pm 103.3 \mathrm{IU} / \mathrm{L}$ and $72.3 \pm 87.8 \mathrm{IU} / \mathrm{L}$ respectively. Patients with falciparum malaria had significantly higher levels of mean bilirubin, AST, urea and creatinine. Patients with hepatic dysfunction had higher rate of complications like renal failure, shock, acute respiratory distress syndrome, and mortality. Interpretation and conclusion: Hepatic dysfunction was more common and more severe in patients with P. falciparum malaria compared to P. vivax malaria. Patients with hepatic dysfunction had higher rates of complications and higher mortality.
\end{abstract}

Keywords: Falciparum malaria, hepatic dysfunction, vivax malaria

\section{INTRODUCTION}

Malaria is a major public health problem, especially in tropical countries. In the south-east Asian region, India alone contributes to $80 \%$ of malaria cases. ${ }^{[1]}$ In India, $60-65 \%$ of the infections are due to $P$. vivax and $35 \%$ due to $P$. falciparum. ${ }^{[2]}$ Earlier considered to be a benign infection, $P$. vivax is now being recognized as a cause of severe and fatal malaria despite its low parasite biomass. ${ }^{[-4]}$ The manifestations of mal-aria infection are changing worldwide with respect to clinical

Corresponding Author: Dr. Omesh Goyal

E-mail: goyalomesh@yahoo.co.in

Received: 04-08-2015

Accepted:02-09-2015

How to cite this article: Goyal O, Prashar S, Puri S. Hepatic dysfunction in falciparum and vivax malaria in northern India. J Gastrointest Infect, 2015; 5:31-37. presentation and complications. Hepatic dysfunction is not uncommon in malaria, being more frequently observed with P. falciparum malaria com-pared to P. vivax malaria. ${ }^{[5-7]}$ The extent of hepatocellular dysfunction varies from mild abnormalities in liver function tests to hepatic failure but hepatic encephalo-pathy is unusual. ${ }^{[5]}$ Patients with hepatocellular dysfunction in malaria are more prone to develop complications, but have a favorable outcome if hepatic involvement is recognized early and managed properly.

Data on comparison of the hepatic dysfunction in $P$. falciparum and vivax malaria is scarce. Studies providing information regarding the disease severity, complications and outcomes of hepatic dysfunction in falciparum and vivax malaria infection are important so that appropriate interventional measures can be adopted at an early stage. The present study aimed to 
assess the incidence, pattern, severity and outcome of hepatic dysfunction in cases of P. falciparum and P. vivax malaria admitted to a tertiary care hospital in northern India.

\section{MATERIALS AND METHODS}

This retrospective observational study was undertaken in a tertiary care hospital in northern India. All hospitalized adult patients (18-80 years) diagnosed to have malaria from January 2013 to December 2013 were included. This institute in Punjab, northern India also caters to the population of other neighboring states like Himachal Pradesh, Haryana, Rajasthan and Jammu and Kashmir.

Records of all malaria patients were reviewed. Detailed history and clinical examination were noted. Laboratory investigation had been carried out as per the treating physician's advice. All laboratory parameters including biochemical and hematological characteristics including complete blood count, blood glucose, blood urea, serum creatinine, serum bilirubin (total and direct), ALT (alanine transaminase), AST (aspartate transaminase), ALP (alkaline phosphatase), serum albumin and INR (International normalized ratio) for prothrombin time were noted. All patients of malaria had been screened for species diagnosis. Detection of species P. falciparum and P. vivax in the affected patient was done from peripheral blood smear and antibody based rapid malaria antigen test. G-6-PD levels, viral markers (including IgM Anti-HAV, IgM Anti-HEV, HbsAg, and Anti-HCV), leptospira serology and dengue serology were done where indicated according to history, examination and other laboratory parameters. All patients received anti-malarial medications as per the hospital policy. Exclusion criteria were concomitant acute viral hepatitis (by history and serological studies), chronic viral hepatitis (by history, clinical examination and/or laboratory evaluation), history of hepatotoxic drug intake in the recent past, history of intake of herbal medicines, history of significant alcohol consumption and patients with incomplete data record.

Liver involvement due to malaria was considered if there was at least three fold rise in alanine transaminase level $(>120 \mathrm{IU} / \mathrm{ml})$ and/or conjugated hyperbilirubinemia of $>3 \mathrm{mg} / \mathrm{dl}$, in the absence of clinical or serological evidence of viral hepatitis. The criteria for severe malaria included serum bilirubin of $>3 \mathrm{mg} / \mathrm{dL}$, renal failure with a serum creatinine of $>3 \mathrm{mg} / \mathrm{dL}$, hypoglycemia with a blood glucose level $<40 \mathrm{mg} / \mathrm{dL}$, shock with a systolic blood pressure of $<90 \mathrm{~mm} \mathrm{Hg}$ despite volume resuscitation and/or severe anemia with a hemoglobin of $<5 \mathrm{~g} / \mathrm{dL}$.

\section{Statistical analysis}

All data were analyzed using SPSS software package. Continuous data were expressed as mean \pm SD . Categorical data were expressed as number/proportion of subjects with a specific feature. Chi-square test was used to compare categorical data. A two-tailed $p$ value of less than 0.05 was required for statistical significance.

\section{RESULTS}

A total of 124 cases of malaria were admitted to the institute over 1 year period. Of these, 9 patients were excluded (3 had underlying cirrhosis, 2 had viral hepatitis, 4 had incomplete data record), and the rest 115 patients were included for further analysis. Of these, 85 $(73.9 \%)$ patients had P. vivax infection, and $30(26.1 \%)$ had $P$. falciparum infection. The mean age was $36.7 \pm 16.1$ years and male: female ratio 2.7:1.

History of fever was present in all the cases and clinical jaundice was seen in $34.7 \%$ (40) cases. Other symptoms were chills $(33.1 \%)$, vomiting $(36.5 \%)$ and abdominal pain (25.2\%). Bleeding episodes were seen in 6 patients (3 had hematuria, 3 had hematemesis/ melena). Overall, liver involvement was seen in $37.4 \%$ (43) patients. The maximum bilirubin level was 35.9 $\mathrm{mg} / \mathrm{dL}$ and the mean value was $3.76 \pm 5.44 \mathrm{mg} / \mathrm{dL}$. Predominantly conjugated hyperbilirubinemia was seen in $88.4 \%$ (38) and predominantly unconjugated hyperbilirubinemia in $11.6 \%$ (5) cases. The mean AST value was $65.8 \pm 72.2 \mathrm{U} / \mathrm{L}$ and the mean ALT value was $51.6 \pm 58.4 \mathrm{U} / \mathrm{L}$. The mean INR value was $1.3 \pm 0.6$ and the mean albumin level was $3.16 \pm 0.6 \mathrm{~g} / \mathrm{dL}$. Ultrasonography (US) showed hepatosplenomegaly in 45 cases, hepatomegaly alone in 12 cases, splenomegaly alone in 9 cases and gall bladder wall thickening was seen in 15 patients.

At presentation, $50 \%$ patients with falciparum malaria had jaundice compared to $29.4 \%$ with vivax malaria, while vomiting and abdominal pain were more commonly reported by patients with vivax malaria compared to falciparum malaria $(41.2 \%$ vs. $23.3 \%$ and 
Table 1

Comparison of laboratory parameters in P. vivax and P. falciparum infection

\begin{tabular}{|c|c|c|c|}
\hline Parameters & $\begin{array}{l}\text { P. vivax infection } \\
(\mathrm{n}=85)\end{array}$ & $\begin{array}{l}\text { P. falciparum } \\
\text { infection } \\
(\mathrm{n}=30)\end{array}$ & $P$ value \\
\hline Hemoglobin (g/dl) & $11.34 \pm 2.1$ & $9.63 \pm 3.03$ & 0.007 \\
\hline Platelets $\times 10^{3} / \mathrm{mm}^{3}$ & $41.2 \pm 37.2$ & $70.5 \pm 68.7$ & 0.0044 \\
\hline Urea (mg/dl) & $41.4 \pm 31.4$ & $80.8 \pm 68.5$ & 0.0001 \\
\hline Creatinine $(\mathrm{mg} / \mathrm{dl})$ & $1.31 \pm 1.29$ & $2.24 \pm 3.7$ & 0.047 \\
\hline Total Bilirubin (mg/dl) & $2.9 \pm 3.4$ & $6.2 \pm 8.8$ & 0.0043 \\
\hline Direct Bilirubin (mg/dl) & $1.72 \pm 2.6$ & $4.5 \pm 6.93$ & 0.002 \\
\hline ALT (IU/L) & $46.4 \pm 62.9$ & $66.5 \pm 54.5$ & 0.119 \\
\hline AST (IU/L) & $50.6 \pm 47.2$ & $108.7 \pm 109.7$ & 0.0001 \\
\hline $\operatorname{ALP}(I U / L)$ & $105.3 \pm 45.9$ & $114.9 \pm 64.4$ & 0.403 \\
\hline Albumin (g/dl) & $3.3 \pm 0.3$ & $2.78 \pm 0.6$ & 0.0001 \\
\hline ARDS & $1(1.2)$ & $2(6.6)$ & 0.166 \\
\hline Shock & $2(2.4)$ & $3(10)$ & 0.110 \\
\hline Hypoglycemia & $1(1.2)$ & $4(13.3)$ & 0.016 \\
\hline Mortality/DAMA & $4(4.7)$ & $4(13.3)$ & 0.203 \\
\hline
\end{tabular}

Data are expressed as mean \pm SD or number (percent). ALT: Alanine transaminase; ALP: Alkaline phosphatase; AST: Aspartate transaminase; ARDS: Acute respiratory distress syndrome, DAMA: Discharged against medical advice

27.1 vs. $13.3 \%$ respectively) Comparison between laboratory parameters and complications in patients with vivax and falciparum malaria is shown in Table 1. Patients with falciparum malaria had significantly higher levels of mean bilirubin, AST, urea and creatinine; significantly higher incidence of hypoglycemia, and significantly lower levels of hemoglobin, platelets and albumin compared to those with vivax malaria.

Hepatic dysfunction was noted in $31.8 \%(27 / 85)$ patients of vivax malaria and 50\% (15/30) patients of falciparum malaria $(\mathrm{p}=0.0826)$. The mean bilirubin, AST and ALT in patients with hepatic dysfunction were $7.7 \pm$ $7.3 \mathrm{mg} / \mathrm{dL}, 97.1 \pm 103.3 \mathrm{IU} / \mathrm{L}$ and $72.3 \pm 87.8 \mathrm{IU} / \mathrm{L}$ respectively. Comparison between degree of elevations in bilirubin, AST and ALT in patients of vivax and falciparum malaria is shown in Table 2.

Comparison between patients with and without liver involvement is shown in Table 3. Among the patients with liver involvement $(n=43)$, significantly higher number of patients $(18.8 \%)$ had serum creatinine value of $>3 \mathrm{mg} / \mathrm{dL}$ compared to only $4.3 \%$ among those without liver involvement $(\mathrm{p}=0.0186)$. ARDS was seen in $4.6 \%$ and $1.4 \%$ cases in the group with and without liver involvement respectively. Severe anemia, hypoglycemia and shock were also more common among patients with liver involvement. The mortality was higher among those with liver involvement compared to those without it $(13.9 \%$ vs. $2.8 \%$ respectively; $\mathrm{p}=0.0507)$.

\section{DISCUSSION}

Hepatic dysfunction in malaria is not uncommon. Cases of hepatic dysfunction are being increasingly reported in patients with malaria infection from different parts of world. In recent years, there has been increasing number of reports of hepatic dysfunction in malaria from Asian countries, especially from India. ${ }^{[5,8]}$ The majority of the cases have either isolated infection 
Table 2

\section{Comparison of degree of derangements of bilirubin, AST and ALT in P. vivax and P. falciparum infection}

\begin{tabular}{|c|c|c|}
\hline Parameters & $\begin{array}{l}\text { P. vivax infection } \\
(\mathrm{n}=85)\end{array}$ & $\begin{array}{l}\text { P. falciparum infection } \\
\qquad(\mathrm{n}=30)\end{array}$ \\
\hline \multicolumn{3}{|c|}{ Total bilirubin (mg/dl) } \\
\hline$<3 \mathrm{mg} / \mathrm{dl}$ & $59(69.4)$ & $15(50)$ \\
\hline $3-5 \mathrm{mg} / \mathrm{dl}$ & $13(15.3)$ & $5(16.7)$ \\
\hline $5-10 \mathrm{mg} / \mathrm{dl}$ & $11(12.9)$ & $5(16.7)$ \\
\hline $10-20 \mathrm{mg} / \mathrm{dl}$ & $1(1.2)$ & $2(6.7)$ \\
\hline$>20 \mathrm{mg} / \mathrm{dl}$ & $1(1.2)$ & $3(10)$ \\
\hline \multicolumn{3}{|l|}{ AST (IU/L) } \\
\hline$<2$ times & $75(88.2)$ & $16(53.3)$ \\
\hline 2-3 times & $7(8.2)$ & $7(23.3)$ \\
\hline 3-5 times & $2(1.4)$ & $5(16.7)$ \\
\hline 5-10 times & $1(1.2)$ & $1(3.3)$ \\
\hline$>10$ times & 0 & $1(3.3)$ \\
\hline \multicolumn{3}{|l|}{ ALT (IU/L) } \\
\hline$<2$ times & $78(91.7)$ & $22(73.3)$ \\
\hline 2-3 times & $5(5.9)$ & $2(6.7)$ \\
\hline 3-5 times & $1(1.2)$ & $5(16.7)$ \\
\hline 5-10 times & 0 & $1(3.3)$ \\
\hline$>10$ times & $1(1.2)$ & 0 \\
\hline
\end{tabular}

Data are expressed as number $(\%)$ or mean \pm SD. ALT: Alanine transaminase; AST: Aspartate transaminase

with $P$. falciparum or a mixed infection with both $P$. falciparum and $P$. vivax..$^{[9-15]}$ The disease spectrum varies from a mild form manifesting with fever, headache and vomiting with minimal abnormality in liver function tests, to severe form presenting with coma, deep jaundice and renal failure and mimicking fulminant hepatic failure. ${ }^{[5,13,15]}$

In the current study, we compared the incidence, pattern, severity and outcomes of hepatic dysfunction in patients with $P$. vivax and P. falciparum infection. In our study, overall $37.4 \%$ patients had hepatic dysfunction in the form of $>3$ times elevation of serum transaminase and/or serum bilirubin levels. The incidence of liver involvement in malaria has varied from $2.45 \%$ to $38 \%$ in various studies. ${ }^{[6,12,13,16]}$ Possible explanations for this wide variation may be the varying geographical conditions, endemicity of malaria in the region from which it is reported, the epidemic forms, the seasonal variations as well as the host factors. ${ }^{[5,17]}$ In addition, different eligibility criteria, operational definitions and data collection methods used in various studies may affect this data. In a study by Anand et al, ${ }^{[13]}$ of the 732 adult patients with falciparum malaria, 39 (5.3\%) patients were noted to have jaundice while Murthy et $a l^{[12]}$ reported jaundice in $62 \%$ of the 95 patients with falciparum malaria. In a study from Poland, ${ }^{[18]} 37 \%$ of the of 121 cases of malarial infection were found to have hepatic parenchymal dysfunction.

Most of the studies on hepatic dysfunction in malaria have reported patients with $P$. falciparum infection. However, studies from various regions have also reported $P$. vivax as a cause of hepatic dysfunction. The incidence of jaundice in P. vivax infection has varied from $0-9 \%$ in these studies. ${ }^{[2,5,19-21]}$ In our study, we 
Table 3

Comparison of clinical and laboratory profile of patients with and without liver involvement

\begin{tabular}{|l|c|c|c|}
\hline Parameter & $\begin{array}{c}\text { Patients with Liver } \\
\text { involvement } \\
\text { (n=43) }\end{array}$ & $\begin{array}{c}\text { Patients without Liver } \\
\text { involvement } \\
\text { (n=72) }\end{array}$ & P value \\
\hline Age (years) & $36.4 \pm 17.2$ & $36.9 \pm 15.5$ & 0.869 \\
\hline Male (\%) & $74.4(32)$ & $72.2(52)$ & 0.832 \\
\hline Hemoglobin (g/dl) & $10.6 \pm 2.2$ & $11.1 \pm 2.6$ & 0.4004 \\
\hline Hemoglobin <9 g/dl & $10(23.2)$ & $15(20.8)$ & 0.392 \\
\hline Platelets x 10 $/ \mathrm{mm}^{3}$ & $44.3 \pm 54.5$ & $53.2 \pm 45.5$ & 0.3422 \\
\hline Urea (mg/dl) & $72.7 \pm 59.9$ & $39 \pm 30.4$ & 0.0001 \\
\hline Creatinine (mg/d) & $1.86 \pm 1.5$ & $1.37 \pm 2.5$ & 0.246 \\
\hline Creatinine $>\mathbf{3} \mathbf{~ m g / d l ~}$ & $18.6 \%(8)$ & $4.2 \%(3)$ & 0.0186 \\
\hline T. Bilirubin (mg/dl) & $7.7 \pm 7.3$ & $1.37 \pm 0.8$ & 0.0001 \\
\hline ALT (IU/L) & $72.3 \pm 87.8$ & $39.2 \pm 21.4$ & 0.0026 \\
\hline AST (IU/L) & $97.1 \pm 103.3$ & $46.9 \pm 32.4$ & 0.0002 \\
\hline ALP (IU/L) & $130.2 \pm 62.4$ & $94.3 \pm 35.9$ & 0.0001 \\
\hline Albumin (g/dl) & $2.8 \pm 0.5$ & $3.35 \pm 0.6$ & 0.0001 \\
\hline ARDS & $2(4.6)$ & $1(1.4)$ & 0.554 \\
\hline Shock & $4(9.2)$ & $1(1.4)$ & 0.0642 \\
\hline Hypoglycemia & $4(9.2)$ & $1(1.4)$ & 0.0642 \\
\hline Mortality/DAMA & $6(13.9)$ & $2(2.8)$ & 0.0507 \\
\hline
\end{tabular}

Data are expressed as mean \pm SD or number (percent). ALT: Alanine transaminase; ALP: Alkaline phosphatase; AST: Aspartate transaminase; ARDS: Acute respiratory distress syndrome, DAMA: Discharged against medical advice

included a good number of patients with both types of infection and found hepatic dysfunction to occur in $50 \%$ patients with $P$. falciparum infection and $38.4 \%$ with P. vivax infection. This data highlights the fact that $P$. vivax infection may not be as benign as previously considered. Few factors like male sex and younger age group have been reported to be associated with increased incidence of hepatic dysfunction in malaria. ${ }^{[16]}$ However, we did not find any such association in our study.

The serum bilirubin levels in P. falciparum infection can vary from $2.5 \mathrm{mg} / \mathrm{dl}$ to $62 \mathrm{mg} / \mathrm{dl} .^{[12,13,17]} \mathrm{In}$ a study of 50 peripheral blood film confirmed cases of $P$. falciparum malaria with jaundice, 18 patients had serum bilirubin $<3 \mathrm{mg} \%$, 20 patients had serum bilirubin between 3-10 $\mathrm{mg} \%$ and only 12 patients had serum bilirubin values of $>10 \mathrm{mg} \%{ }^{0}{ }^{[10]}$ In a study by Anand et al ${ }^{[13]}$ the mean serum bilirubin was $12.7 \mathrm{mg} / \mathrm{dl}$, serum AST was $212.8 \mathrm{IU} / \mathrm{L}$ and serum ALT was $287 \mathrm{IU} / \mathrm{L}$. Malhotra et $\mathrm{l}^{[22]}$ reported mean total bilirubin level of $21 \mathrm{mg} / \mathrm{dL}$ (1.5-54), mean AST and
ALT of 164.84 IU/L (38-665) and 75 IU/L (43-160) respectively. ALT $>3$ upper limit of normal was seen in $15.38 \%$ cases. In the present study, the mean value of bilirubin $(7.7 \pm 7.3 \mathrm{mg} / \mathrm{dL})$, AST $(97.1 \pm 103.3)$ and ALT $(72.3 \pm 87.8 \mathrm{IU} / \mathrm{L})$ values were lower than the previous studies indicating a milder liver involvement in our study. However, a consistent finding in all the studies has been a disproportionate rise in serum bilirubin with mild elevation of liver enzymes. This is an important observation which can help to differentiate these patients from viral hepatitis.

There is also a wide variation in the type of bilirubin (conjugated/unconjugated) elevation patients with malaria. ${ }^{[10,23,24]}$ The type of bilirubin rise in malaria depends on the underlying pathophysiology. Patients with predominant hemolysis have unconjugated hyperbilirubinemia while those with hepatic dysfunction have conjugated hyperbilirubinemia. The parasite, especially $P$. falciparum, infects a large number of cells which are then destroyed in the spleen, resulting in 
hemolytic anemia and unconjugated hyperbilirubinemia with near normal liver enzymes.

Hepatic dysfunction in malaria may occur due to various reasons like failure of bilirubin excretion, endotoxemia, ischemia, acidosis or a combination of the above mentioned factors. ${ }^{[1,1,17]}$ Ischemic injury to the liver occurs due to sequestration of the parasite-infested red blood cells in the liver capillaries cause clogging of the capillaries. ${ }^{[5]}$ Hepatic dysfunction leads to rise in conjugated bilirubinemia and transaminitis. Jaundice in malaria could also be due to coexistent viral hepatitis, which should be excluded by serological studies. Alternative or herbal medicines commonly used in fever/jaundice can also contribute to hepatic dysfunction which may worsen the picture in severe malarial infection. Saya et al ${ }^{[16]}$ reported conjugated hyperbilirubinemia in $68 \%$ of the cases in their study, while other studies had reported predominantly unconjugated hyperbilirubinemia. ${ }^{[23,24]}$ Similar to the former study, majority $88.4 \%$ of the patients in our study had predominantly conjugated hyperbilirubinemia.

The presence of hepatic dysfunction on malaria indicates a more severe illness with a higher incidence of complications and a poor prognosis. In a study by Murthy et al, 20 out of 95 patients with falciparum malaria had evidence of malarial hepatitis. ${ }^{[12]}$ The incidence of complications such as renal failure (60\% vs. $25 \%)$, Acute Respiratory Distress syndrome (ARDS) $(35 \%$ vs. $3 \%)$ and septicemia $(20 \%$ vs. $6 \%)$ was significantly higher in patients with hepatic dysfunction. The mortality too was higher in patients with malarial hepatitis (40\% vs. $17 \%$ ). In another study from Thailand, 124 out of 390 patients with acute falciparum malaria who had hepatic dysfunction, had more complications in the form of cerebral malaria, acute renal failure, pulmonary edema and shock. ${ }^{[23]}$ Many other studies have also reported similar data. ${ }^{[1,16]}$ In our study too, patients with hepatic dysfunction had higher incidence of renal failure, ARDS and shock.

Our study has a few limitations. This was a retrospective hospital based study. Patients with mild cases of malaria with hepatic dysfunction who do not visit a tertiary care hospital may have a different disease pattern and different outcome. Therefore, the findings of this study cannot be generalized to the community. Secondly, liver biopsy and histopathological examination was not done in these patients. In spite of these limitations, the study provides valuable information on the pattern of hepatic dysfunction in both vivax and falciparum malaria which can be utilized for early recognition and treatment to avoid complications.

To conclude, hepatic dysfunction occurs in both falciparum and vivax malaria, though it is commoner and more severe in the former. Patients with hepatic dysfunction have higher rates of complications and higher mortality. In areas endemic for malaria, awareness of this entity is important for early and appropriate treatment. In a patient with fever and jaundice, disproportionate hyperbilirubinemia with only mild elevation of liver enzymes could help differentiate these cases from viral hepatitis.

Source of funding: Departmental funds

CONFLICT OF INTEREST: There is no potential conflict of interest

\section{REFERENCES}

1. WHO. World health report 2008. Geneva. World Health Organisation. 2008

2. Nadkar MY, Huchche AM, Singh R, Pazare AR. Clinical profile of severe $P$. vivax malaria in a tertiary care centre in Mumbai from June 2010-January 2011. J Assoc Physicians India. 2012;60: 11-3.

3. Barcus MJ, Basri H, Picarima H, Manyakori C, Sekartuti, Elyazar I, et al. Demographic risk factors for severe and fatal vivax and falciparum malaria among hospital admissions in north-eastern Indonesian Papua. Am J Trop Med Hyg. 2007;77:984-91.

4. Tjitra E, Anstey NM, Sugiarto P, Warikar N, Kenangalem E, Karyana $M$, et al. Multidrug-resistant Plasmodium vivax associated with severe and fatal malaria: a prospective study in Papua, Indonesia. PLoS Med. 2008;5:e128.

5. Bhalla A, Suri V, Singh V. Malarial hepatopathy. J Postgrad Med. 2006;52:315-20.

6. McMohan AE Jr, Kelsy JE, Deranf DE. Hepatitis of malarial origin: Clinical and pathologic study of fifty-four Korean veterans. AMA Arch Int Med. 1954;93:379-86.

7. Wali PN, Tandon HD. Malarial Hepatitis. J Indian Med Assoc. 1955;13:507:11.

8. Severe falciparum malaria. World Health Organization, Communicable Diseases Cluster. Trans R Soc Med Hyg. 2000;94:S1-90.

9. Devarbhavi H, Alvares JF, Kumar KS. Severe falciparum malaria simulating fulminant hepatic failure. Mayo Clin Proc. 2005;80:355-8.

10. Kochar DK, Singh P, Agarwal P, Kochar SK, Pokharna R, Sareen PK. Malarial hepatitis. J Assoc Physicians India. 2003;51:106972.

11. Kochar DK, Agarwal P, Kochar SK, Jain R, Rawat N, Pokharna $\mathrm{RK}$, et al. Hepatocyte dysfunction and hepatic encephalopathy in Plasmodium falciparum malaria. QJM. 2003;96:505-12. 
12. Murthy GL, Sahay RK, Sreenivas DV, Sundaram C, Shantaram V. Hepatitis in falciparum malaria. Trop Gastroenterol. 1998;19:1524.

13. Anand AC, Ramji C, Narula AS, Singh W. Malarial hepatitis: A heterogeneous syndrome? Natl Med J India. 1992;5:59-62.

14. Arya TV, Prasad RN. Malarial hepatitis. J Assoc Physics India. 1988;36:294-5

15. Joshi YK, Tandon BN, Acharya SK, Babu S, Tandon M. Acute hepatic failure due to Plasmodium falciparum liver injury. Liver. 1986;6:357-60.

16. Saya RP, Debabrata G, Saya GK. Malarial Hepatopathy and Its Outcome in India. NAm J Med Sci. 2012; 4:449-52.

17. Anand AC, Puri P. Jaundice in malaria. J Gastroenterol Hepatol. 2005;20:1322-32.

18. Goljan J, Nahorski W, Felczak-Korzybska I, Gorski J, Myjak P. Liver injury in the course of malaria. Int Marit Health. 2000;51:30-9.

19. Hazra BR, Chowdhury RS, Saha SK, Ghosh MB, Mazumdar AK. Changing Scenario of malaria: A study at Calcutta. Indian J Malariol. 1998;35:111-6.
20. Echeverri M, Tobon A, Alvarez G, Carmona J, Blair S. Clinical and laboratory findings of Plasmodium vivax malaria in Colombia. Rev Inst Med Trop Sao Paulo. 2003;45:29-34.

21. Seth AK, Nijhawan VS, Bhandari MK, Dhaka RS. Malarial hepatitis: Incidence and liver morphology. Indian J Gastroenterol. 1997; 16:A107.

22. Malhotra $\mathrm{P}$, Malhotra N, Malhotra V, Chugh A, Chaturvedi A, Dahiya $\mathrm{H}$, et al. Malarial Hepatopathy-Experience at Tertiary Care Centre of North India. The Indian Practitioner, [S.I.], p. 29-30, may. 2015. ISSN 2394-3017. Available at: <http://theindianpractitioner. com/ index.php/tip/article/view/70348>. Date accessed: 31 Jul. 2015.

23. Wilairatana $\mathrm{P}$, Looareesuwan $\mathrm{S}$, Charoenlarp $\mathrm{P}$. Liver profile changes and complications in jaundiced patients with falciparum malaria. Trop Med Parasitol. 1994;45:298-302.

24. Harris VK, Richard VS, Mathai E, Sitaram U, Kumar KV, Cherian AM et al. A study on clinical profile of falciparum malaria in a tertiary care hospital in south India. Indian J Malariol. 2001;38: 19-24. 